\title{
Estudios
}

\section{¿Se da lenguaje en los simios?}

\section{E. Sue Savage-Rumbaugh ( $\left.{ }^{*}\right)$ Duane M. Rumbaugh Sarah Boysen}

\section{Un equipo de investigadores revisa la evidencia en favor de la capacidad de representación simbólica de los si- mios}

FUENTE: American Scientist, 1980, vol. 68, n. ${ }^{\circ} 1$, págs. 49-61.

Las investigaciones sobre el lenguaje en simios están teniendo un profundo efecto en campos como la lingüística (Brown, 1973; Mounin, 1976), la psicología (Limber, 1977), la antropología (Hill, 1978), la zoología (Griffin, 1976), la sociología (Meddin, 1979) y la neurobiología (Steklis y Raleigh, 1979). El amplio impacto de estas investigaciones no se debe a que estén sien- do desarrolladas por equipos multidisciplinares - de hecho se trata únicamente de psicólogossino a que en todas ellas subyace una interrogante clave, a saber: ¿Es el hombre radicalmente distinto del resto de los animales? Si esta cuestión de la singularidad del hombre no fuese una premisa básica de la investigación que se realiza en múltiples campos científicos, el trabajo sobre

(*) Sue Savage-Rumbaugh obtuvo el Ph. D. en la Universidad de Oklahoma en el departamento de Psicologia y es la investigadora principal del proyecto de lenguaje animal del Yerkes Regional Primate Research Center de la Universidad de Emory. Sus intereses se centran en la comunicación de los primates y en el desarrollo y evolución de la inteligencia. Su marido, Duane M. Rumbaugh, es Decano y profesor del departamento de Psicología de la Georgia State University, coordinador del Language Formation Studies Program con chimpancés en Yerkes Laboratories y con niños retrasados mentales en el Georgia Retardation Center de Atlanta, y colaborador científico en el Yerkes Center. Es doctor por la Universidad de Colorado. Sus intereses se centran en la Comunicación, el aprendizaje en primates y la inteligencia en los primates. Sarah Boysen tiené el «master» en Psicología por la Universidad de Oklahoma. Es estudiante de doctorado de Psicología de la Universidad estatal de Georgia y está interesada principalmente en la conducta social de los primates y su comunicación. Trabaja con chimpancés en el Yerkes Primate Center, en el proyecto dirigido por la doctora Savage-Rumbaugh. La preparación de este artículo y la investigación se ha realizado gracias a las becas NIH de referencia NICHO-06016 y RR-00165. Dirección de los autores: Yerkes Regional Primate Center, Emory University, Atlanta, GA 30322. 
el lenguaje de los simios no estaría atrayendo la atención de la manera tan general como lo hace. Tal como señala Hill, este trabajo «podría suponer un cambio de paradigma en el que Platón dejara paso definitivamente a Darwin o incluso "una crisis de identidad en el Homo Sapiens" (Gallup et al. 1977, p. 303)». (Hill, 1978, p. 89.)

Una investigación de tal trascendencia ha de prestar especial atención a sus métodos, resultados y conclusiones. Desgraciadamente, los informes sobre el lenguaje en simios ha tratado de forma un tanto superficial muchos de los aspectos fundamentales del lenguaje. La adquisición de la capacidad simbólico-representativa ha sido presentada como algo fácilmente realizable para los chimances, y la cuestión de qué es lo que constituye la función simbólica o representacional ha recibido una atención mínima. Aunque algunas de las críticas iniciales habían puesto en duda la capacidad de los chimpancés a la hora de entender los símbolos que utilizaban (Lenneberg 1971; Sebeok 1972), tales trabajos fueron rápidamente olvidados (Dingwall, 1979) centrándose el interés en los aspectos sintácticos (Mounin, 1976; Limber, 1977).

\section{INVESTIGACIONES SOBRE EL LENGUAJE EN SIMIOS}

Ha habido tres líneas básicas en los intentos de enseñar habilidades lingüísticas a los simios, cada una de las cuales ha utilizado un sistema de comunicación diferente y unas técnicas de entrenamiento también diferentes. Beatrice y Allen Gardner, que inicialmente trabajaron con un chimpancé hembra llamado Washoe, y más recientemente con otros cuatro chimpancés, eligieron el camino de educar a sus animales de la forma más parecida posible a como se educa a los ninos humanos y utilizaron, como medio de comunicación, el ASL (siglas que corresponden a un lenguaje de signos para sordos, desarrollado en EE. UU. y denominado "American Sign Language of the Deaf $)$. El trabajo con Washoe comenzó cuando tenía un año y continuó durante cinco años, momento en el que se aseguraba que había alcanzado un vocabulario de 132 signos, dado que los había ejecutado (cada uno de ellos) según un cierto criterio y durante un cierto número de días. Se informó de que era capaz de producir diversas combinaciones nuevas tales como «Tú a-mí esconder» o «Tú a-mí ir fuera allí rápido» (1), y los Gardner llegan a la conclusión de que Washoe puntúa por encima de los niños que en la escala de Brown alcanzan el Nivel III, e incluso superiores (Gardner y Gardner, 1969, 1971, 1972, 1973, 1974 a y b; 1975, 1978, a y b).

Siguiendo este trabajo pionero, un alumno de los Gardner, Roger Fouts, comenzó a enseñar ASL a seis chimpancés en la Universidad de Ok. lahoma. Fouts continuó también el trabajo con Washoe, aunque de forma intermitente. Utilizó la misma técnica que había sido utilizada con Washoe: obligar al simio a colocar las manos en la forma que corresponde a cada signo,reduciendo progresivamente la exactitud y la fuerza con que se le dirige hasta que el animal aprende a colocar correctamente las manos por sí mismo. A diferencia de los Gardner, Fouts permitía que se hablara el inglés oral en presencia de los chimpances (Fouts, 1972, 1973, 1974; Fouts, Chowin y Goodin, 1976; Fouts, Chowin y Kimball, 1976; Fouts y Mellgren, 1976).

Poco tiempo después de que Fouts comenzara su trabajo en Oklahoma, Penny Patterson (1978) comenzaba un estudio similar con un gorila llamado Koko. Al igual que Fouts, esta investigadora forzaba las manos del gorila para que formara los signos y permitía que el gorila oyese el lenguaje hablado. Ambos, Fouts y Patterson, utilizaron un criterio de adquisición de palabras similar al de los Gardner.

Herbert Terrace inició en 1974 un proyecto de lenguaje de signos, con un chimpancé llamado Nim (nacido en Oklahoma). Este investigador, al igual que los Gardner y Patterson, educó a Nim tal como se educa a los niños, e intentaba fomentar la comunicación con respecto a todo lo que constituye la vida cotidiana. A Nim se le enseñó a hacer los signos con un método basado en los de Gardner y Fouts. Terrace realizó la primera grabación en video de un estudio sobre el uso de signos por los simios, y resultó que este registro de los progresos que hacía Nim supuso finalmente que él y sus colaboradores llegaran a unas conclusiones sobre la capacidad de hacer signos de los simios, que diferían de las de los restantes investigadores de estas cuestiones (Terrace, 1979; Petrito y Seidenberg, 1979; Seidenberg y Pettito, 1979).

(1) Dadas las dificultades que aparecen al intentar traducir al castellano la traducción al inglés que los autores hacen de los signos de que se compone el lenguaje, se ha optado por tratar de transmitir el sentido y el número de palabras de cada frase prescindiendo de una traducción literal, que resultaría ininteligible. Cuando dos palabras aparecen unidas por un guión (por ejemplo a-mí o por-favor) corresponden a una sola palabrasigno. Se ha tratado de respetar la concordancia del género en castellano, aunque en inglés y en el lenguaje de signos no se dá (por ejemplo, en el caso de las frases «Washoe buena» y «Ron bueno», se utiliza el mismo signo para bueno-a). Nota del $\mathrm{T}$. 
Dado que todos estos trabajos sobre el lenguaje de signos en los simios siguen los procedimientus establecidos por los Gardner, sólo discutiremos detalladamente los logros de Washoe, ya que es la más conocida de todos los simios que utilizan el lenguaje de los signos. Sin embargo, todo lo que se diga será igualmente aplicable a los restantes casos ya que todos comparten el mismo tipo de entrenamiento y por tanto los mismos problemas metodológicos que vamos a discutir en el caso de Washoe.

David Premack enseñó a la chimpancé hembra Sarah a elegir, bajo ciertas condiciones, una serie de fichas de plástico a las que el investigador había asociado varias palabras inglesas. La tarea en concreto consistía en que Sarah tenía que elegir una ficha de entre dos u ordenar cuatro o cinco fichas en una secuencia dada. Según Premack la conducta de elección de fichas de Sa. rah era equiparable a la de pronunciar palabras. Por ejemplo, Premack colocaba delante de Sarah un dulce y tres fichas. A cada ficha le había asig. nado un nombre de comida tal como "caramelo», "plátano" y «naranja». Cuando Sarah elegía la ficha que previamente había sido estipulada como «caramelo" se consideraba que estaba nombrado y pidiendo el caramelo. Premack continuó estas pruebas de elección con conjuntos más complejos de fichas que representaban palabras inglesas; una prueba, por ejem. plo, incluía la elección de fichas que se suponía representaban el indicador de plural, ante otras fichas que decían «rojo amarillo ?? color».

Rumbaugh, Warner y Von Glasersfeld (1977) trataron de desarrollar un mérodo para el estudio de la adquisición de lenguaje en simios, que combinase los aspectos más interesantes de los enfoques de los Gardner y de Premack y que al mismo tiempo evitase sus aspectos problemáticos. Para ello crearon un medio de comunicación simbólica que permitiese construir un conjunto completo de frases pero cuyos elementos no tu. viesen significado tomados individualmente. El medio de comunicación que desarrollaron permitía también eliminar los problemas de las.posibles pistas que suministra el investigador, ya que la selección de símbolos la realizaba un ordenador. A diferencia de los trabajos anteriores, las «palabras» en este sistema estaban compuesta por un número limitado de elementos que eran combinados de diversas maneras, para formar $\mathrm{fi}_{\text {- }}$ guras geométrica (por ejemplo: $\$$ = Sugus, $\phi=$ ! zumo, $\odot=$ l flan, $\phi=$. letrina). En un principio se exigía a Lana que apren- diera cadenas de símbolos para operar los dispensadores de comida y los aparatos mecánicos que había en su entorno (por ejemplo, por favor máquina dar Sugus o por favor máquina bacer ventana abrir). Posteriormente el animal captó que las máquinas debían ser cargadas por los hombres y rápidamente transfirió la utilización de estas cadenas de símbolos a su relación con los entrenadores (por favor Tim dar lecbe fuera cuarto) (2). Lana realizaba tales peticiones a base de pulsar botones, señalados con los símbolos geométricos, que estaban dispuestos en un panel (véase Figura 1). Tales botones eran intercambiables al objeto de evitar el aprendizaje posicional.

Sherman y Austin, dos jóvenes chimpancés machos se añadieron al proyecto Yerkes en 1976. Su entrenamiento fue distinto al de Lana en el sentido de que no se les enseñó a producir cadenas de símbolos, no fueron limitados por la misma gramática y fueron educados y entrenados en un medio social similar al de un niño de edad preescolar. Se hizo especial hincapié en la comunicación inter-animal desde el comienzo del entrenamiento, lo cual produjo un desarrolo de las habilidades receptivas y designativas que no se había encontrado en otros simios. A diferencia de Lana, el medio de comunicación de Sherman y Austin no había sido limitado al panel de símbolos. Por el contrario se habían utilizado gestos espontáneos humanos y de los chimpancés (no ASL), vocalizaciones e incluso tareas similares a las de Premack. No es posible hacer aquí una detallada descripción de estos trabajos, sin embargo, deseamos señalar que las dificultades encontradas en el entrenamiento de Austin y Sherman han dado pie a muchas de las opiniones que se postulan en este trabajo (SavageRumbaugh y Rumbaugh, 1976, 1979, en prensa; Savage-Rumbaugh, 1979; Savage-Rumbaugh et al., 1979 a, b, en prensa).

Signos, lexigramas y fichas de plástico, han sido considerados como verdaderos elementos de un vocabulario en los simios, siempre que estos demuestren ser capaces de ejecutar la etiqueta conductual correcta en presencia del correspondiente hecho u objeto. Tanto los tres programas del lenguaje iniciales como los tres derivados, parten de esta suposición básica.

Pero la cuestión es: ¿ Se pueden considerar equivalentes la simple capacidad de etiquetar y la capacidad de representar simbólicamente? ¿Entienden verdaderamente los simios que un signo, un lexigrama, o una ficha'de plástico, pue-

(2) Las máquinas dispensadoras de comida y bebida de este experimento se cargaban a través de cajas receptoras que se encontraban fuera de la habitación en que estaba Lana, pero que ésta podía ver desde dentro de su habitación (N. del T.). 


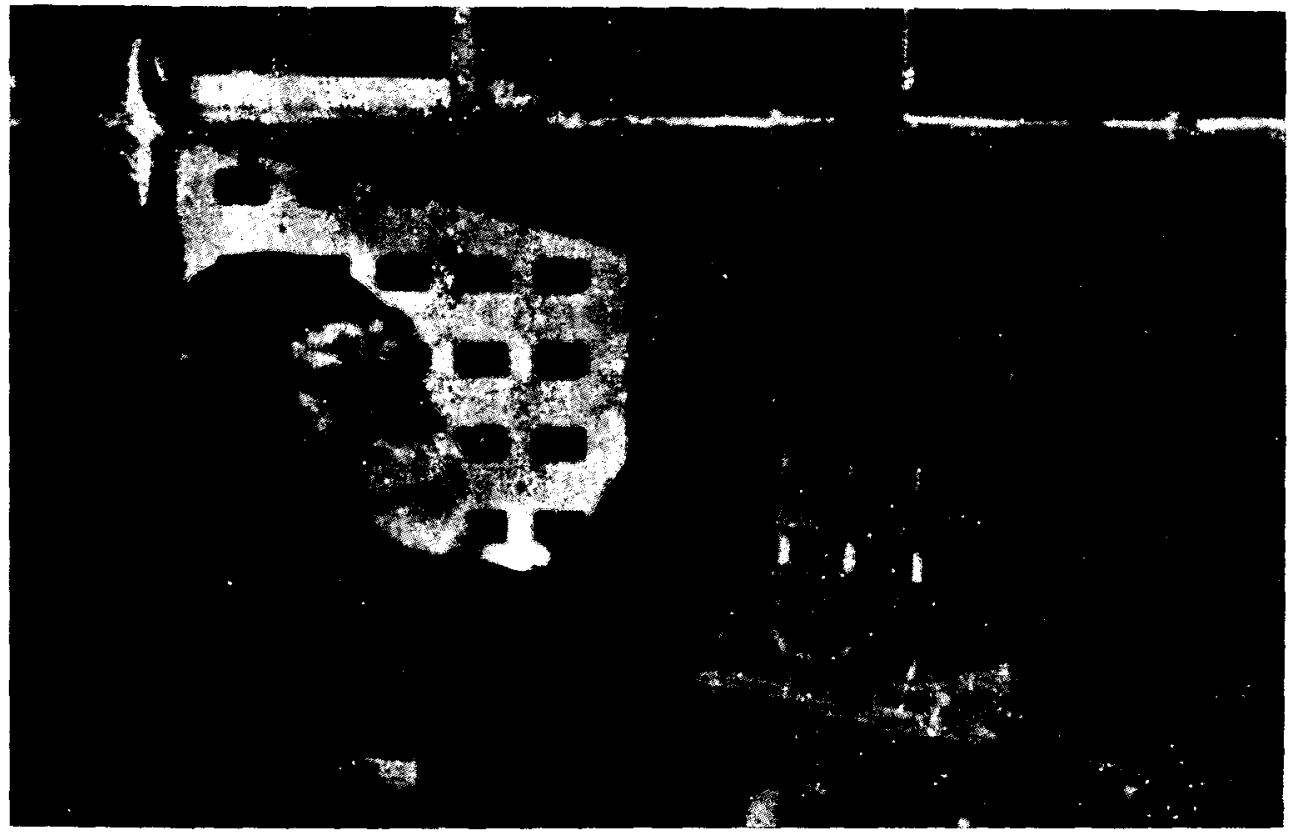

Figura 1.-Lana, el chimpancé utilizado en el experimento inicial de los autores, se sienta delante del panel en el que manipula los signos. El autor se cuestiona hasta qué punto Lana y otros simios han sido capaces, verdaderamẹnte, de utilizar los símbolos para representar cosas.
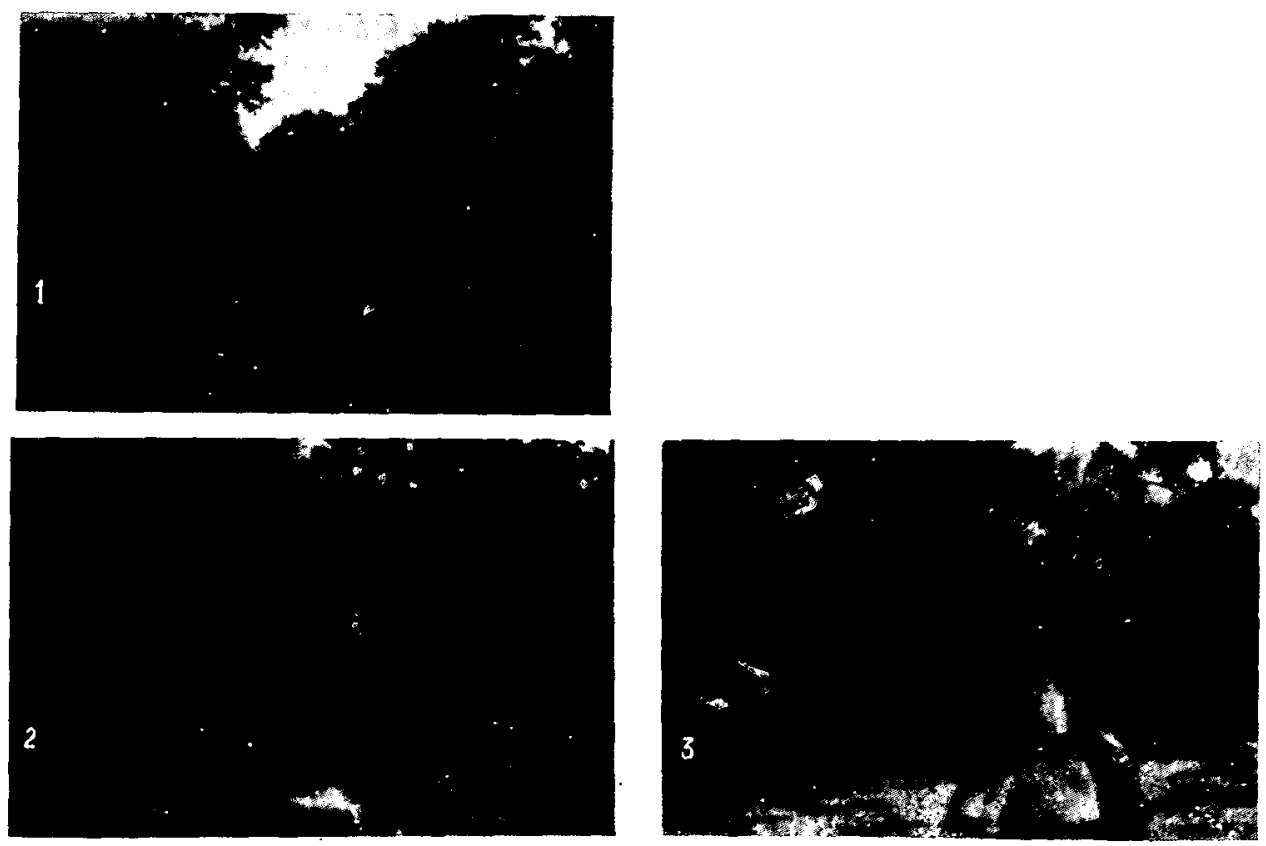

Figura 2.-Un chimpancé joven llamado Lilith. mantenido como animal doméstico y al que nunca se le enseñó a hacer signos, reacciona ante la marcha de su madrastra humana. Según el criterio de los Gardner y de Fouts, el animal estaría haciendo los signos (de derecha a izquierda) de arriba», «abrazar» (con una mano) y aven» (fotos de E. Sue Savage-Rumbaugh). 
den representar a un objeto que podría estar ausente en el tiempo o en el espacio? ¿Sabe, verdaderamente, el simio que un nombre puede ser utilizado para transmitir, a otro ser vivo, una información acerca de un objeto? ¿Se logra crear una representación simbólica mediante la simple asociación entre un suceso y objeto y una respuesta? La cuestión de si la asociación de etiquetas y hechos en los simios es equivalente a la utilización representacional que los niños hacen de los nombres es el punto clave de la cuestión. La capacidad combinatoria, la sintaxis y la utilización novedosa son todas ellas cuestiones subordinadas a lo anterior.

\section{¿QUE ES LA REPRESENTACION SIMBOLI- $C A$ ?}

Hasta recientemente los lingüístas y psicólo. gos evolutivos no se han ocupado de este tema, pero hay un acuerdo prácticamente general en cuanto a los aspectos referenciales del nombrar. Pylyshyn (1977) señala que: aLos animales pueden aprender a dar iespuestas, o mands tal como las llama Skinner, que son instrumentales con respecto a la obtención de objetos concretos. Pero esto es sólo parte de lo que constituye la capacidad de nombrar. Nombrar un objeto implica que el objeto ha sido aislado o sacado conceptualmene de su contexto, quedando disponible para su libre manipulación cognitiva. Por esto para un niño el aprender incluso algo tan aparentemente simple como el nombre de un objeto es todavía una actividad que implica una alta elaboración cognitiva. Lo que parece conferir a esta relación (la relación entre el nombre y el objeto) un estatus diferente del de la simple asociación, es el hecho de que se forma en un contexto especial en el que la atención se centra en la relación referencial (no asociativa). (1977, p. 40).»

Los lingüístas consideran la representación o simbolización como un sistema que permite referirse a objetos y sucesos que no están presentes $y$, por tanto, ofrece a quien lo utiliza una capacidad de comunicación que va mucho más allá de los esquemas no verbales del tipo accióngesto (Nelson, en prensa; Bruner, 1973, 197475). Se puede comunicar una gran cantidad de mensajes a base de señalar y hacer gestos, pero la interpretación exacta de tales mensajes depende totalmente de su relación con el contexto extralingüistico y no verbal en el que se producen. Para que el señalar sea efectivo, el objeto de referencia ha de estas físicamente presente; en cambio, si se puede utilizar un símbolo en lugar del objeto éste puede ser representado mediante un conocimiento compartido que está almacenado en los cerebros de ambos comunicantes sin que sea necesaria la presencia del objeto. Lo esencial en el lenguaje es pecisamente esto, «la conversión de significados (es decir conocimiento de gente, objetos, sucesos y sus relaciones) en palabras, y la trasmisión de estos significados a otro ser social, por alguna razón funcional. Recíprocamente incluye la interpretación del signifi. cado transmitido por los otros al niño y la apropiada respuesta al propósito funcional del mensaje» (Nelson, en prensa).

Por tanto, cualquier caso de auténtica representación lingüistica que se tome incluye al menos cuatro componentes: Primero, un símbolo arbitrario que representa a yuede utilizarse en lugar de, un objeto real, hecho, persona, acción o relación; segundo, conocimiento almacenado de la acción, objeto y relación a que haga referencia dicho símbolo (este conocimiento almacenado no será igual en todos los comunicantes, pero cuanto mayor sea el grado de solapamiento más precisa será la comunicación); tercero, la utilización intencional de ese símbolo para transmitir dicho conocimiento almacenado a otros sujetos que posee experiencias reales similares, asociadas al mismo sistema simbólico, y cuarto, la adecuada descodificación de y respuesta a, el símbolo, por parte del receptor.

Hay pensamiento representacional que no es representación simbólica. El pensamiento representacional presupone una representación cognitiva interna de un objeto, acción... etc., en su ausencia, lo que permite la realización de operaciones cognitivas sobre objetos y acciones, sin recurrir a operaciones sensoriomotoras. Esta habilidad de re-presentarse (a si mismos) los hechos permite a los organismos resolver problemas mediante un proceso que se ha denominado insight, en lugar de hacerlo mediante ensayo y erros. En otras palabras, el proceso de ensayo y error se interioriza de manera que se pueden poner a prueba distintas alternativas de forma encubierta, es decir, mediante una acción no observable.

La representación simbólica se distingue de la simple re-presentación de las experiencias, es una forma de representación interindividual. Presupone la existencia de símbolos, preferiblemente arbitrarios. Un sistema pictórico no simbólico podría permitir también a los sujetos el representarse cosas (tal como probablemente los primeros hombres representaban y comunicaban aspectos de la caza, mediante las pinturas rupestres); sin embargo, tal sistema sería muy lento y dificultoso, entorpeciendo el intercambio comunicativo.

No podemos hablar de evidencia de representación simbólica hasta que no queda demostrado que se producen operaciones cognitivas incluso cuando un sujeto dispone sólo de información 
simbólica. La existencia de tales operaciones cognitivas pueden ser inferidas si, y sólo si, es necesaria una reorganización o reestructuración interna para que un organismo alcance la conducta final observada.

Los investigadores e incluso quienes los critican asumen demasiado pronto que cuando un simio utiliza un símbolo, posee un referente mental que le lleva a hacerlo. Por ejemplo, cuando Washoe hace el símbolo beber sin que se le haya preguntado qué es una bebida, se supone que Washoe tiene en mente el referente, una bebida concreta, y que está tratando de transmitir un mensaje referente a bebidas (Fouts, comunicación personal). Si es verdad que Washoe entiende su propia frase "Tú más beber» y que la dice por la misma razón que un ser humano produciría una frase similar - es decir, para producir una repetición del acto que acaba de ocurrir, en el que el compañero ha bebido- esto implicaría: primero, que Washoe puede producir símbolos sin que el objeto sea presentado o señalado por el experimentador, e incluso sin la presencia del objeto; segundo, que el objetivo de la producción simbólica de Washoe es transmitir información a un interlocutor-receptor acerca de sus «pensamientos» o decisiones privadas; tercero, que Washoe presupone que el uso de este símbolo producirá una imagen o representación de algún tipo en el cerebro del receptor, y cuarto, que cuando se suministra tal información simbólica al cerebro del receptor ello hará que éste varíe el curso de su conducta de acuerdo con la petición. Es importante notar que tales presupuestos nunca han sido demostrados, y que ni siquiera se ha tratado de comprobarlos.

De hecho, no se ha desarrollado un marco teórico, dentro del campo de la psicología animal, que permita distiguir la respuesta discriminativa condicionada de las respuestas simbólico-representacionales. Una simple etiqueta o nombre dichos por un niño se supone que es representacional y que puede ser utilizado en distintas comunicaciones semánticas (peticiones, declaraciones de intención, anuncios... etc.), pero tal capacidad de representación simbólica ha sido generalmente considerada como específica del hombre y las teorías explicativas de tal adquisición no suelen ser consideradas como aplicables a los animales. La habilidad de una paloma para picotear selectivamente un disco rojo para obtener comida y otro verde para lograr agua, como, por ejemplo, en el estudio de Jenkins y Moore (1973) no se ha supuesto nunca que indicará que la paloma picoteaba el disco rojo para representar (simbolizar) comida y que podría picotear tal disco para pedir comida, para anunciar que la comida está presente, para preguntar si hay comida, etc., etcétera.

Sin embargo, los investigadores que comenzaron a enseñar lenguajes a los simios lo hicieron con un sesgo hacia una serie de presupuestos que, sin embargo, estaban reservados exclusivamente para los niños humanos. Dichas sencillamente estas presuposiciones eran que: primero, para que un chimpancé aprendiese un lenguaje debería empezar por aprender cuáles de los símbolos de un conjunto arbitrario han de ser asociados con cuales hechos u objetos; segundo, a medida que el chimpancé aprende estas asociaciones, las relacionará con una capacidad propia de comunicación representacional y simbólica, que le permitirá utilizar tales símbolos de múltiples formas, y tercero, el criterio decisivo para determinar si el chimpancé está aprendiendo verdaderamente un lenguaje será el hecho de que desarrolle o no la capacidad de generar combinaciones inéditas.

Cuando comenzaron los trabajos sobre el lenguaje en simios, estas asunciones reflejaban la aceptación - general en ese momento- de la idea de que el aprendizaje de palabras individuales podía ser fácilmente explicado mediante procesos asociativos relativamente simples, pero que el aprendizaje de etiquetas verbales que ocurría en los niños implicaba la existencia de capacidades comunicativas simbólicas representacionales y funcionales. Este punto de vista -muy extendido en psicología - fue expuesto por primera vez por Skinner $(1953,1957)$ y queda claramente explicado por Jenkins y Palermo (1964), cuando dicen: «Pensamos que los correlatos asociativos entre la conducta verbal y los sucesos en el medio del sujeto que aprende el lenguaje, aparecen rápidamente mediante las sencillas leyes del aprendizaje E (estímulo)-R (respuesta), siendo el aetiquetar o unombrar» en su sentido más amplio una de las primeras cosas que tienen que aparecers (p. 62).

Dado que los tres programas de investigación del lenguaje en simios trataban, desde el principio, de demostrar que sus animales eran capaces de hacer mucho más que simplemente nombrar objetos, no prestaron mayor atención al propio proceso de nombrar objetos. No hubo ningún intento de determinar qué capacidades semánticas estaban implicadas en el proceso de nombrar objetos y tampoco se intentó mostrar -excepto en algún caso aislado - que los símbolos o signos aislados hacían referencia verdaderamente a objetos, hechos o estados motivacionalesintencionales.

En nuestra opinión la representación o la sim. bolización no está implicada en la capacidad de los simios de elegir un símbolo cuando se les 


\section{Estudios}

presenta un objeto, acción o situación, mientras que tales capacidades sí pueden encontrarse en el caso de los niños humanos (Greenfield, 1979). Esto constituye una crítica mucho más grave para los trabajos sobre lenguaje en simios, que la que recientemente han realizado Terrace y sus colaboradores (1979), quienes llegan a la conclusión de que la sintaxis, tal como se da en los seres humanos, no existe en la comunicación simbólica de los simios. Si Nim, el chimpancé de Terrace, hubiese entendido la componente referencial de todos los símbolos que utilizaba, su sintaxis habría podido ser bastante correcta. Pero una investigación sobre la sintaxis, cuando no hay prácticamente evidencia de que se esté produciendo una comprensión semántica, nos llevará inevitablemente a una conclusión negativa respecto de la similitud entre las frases de los simios y las humanas.

Según nuestras propias investigaciones recientes, la habilidad para utilizar símbolos de forma representativa puede ser alcanzada por el chimpance, pero no es posible deducir de la simple asociación entre etiqueta y objeto la existencia de esta función de representación o simbolización. El que el animal sea capaz de poner etiquetas no es condición suficiente para afirmar que los símbolos son palabras o elementos de un vocabulario simbólico del chimpancé. Por des. gracia, la excesiva amplitud con que los investigadores que trabajan con chimpancés han interpretado la conducta de sus sujetos les ha llevado a cometer errores significativos a la hora de interpretar lo que los chimpances son capaces de hacer desde un punto de vista lingüístico, lo que efectivamente han alcanzado, lo que supone lo que han logrado, y lo que se refiere a cómo adquieren estos sujetos sus habilidades lingüísticas.

\section{LA EVIDENCIA EN FAVOR}

DEL LENGUAJE EN SIMIOS

Premack (1975) parece consciente del problema que supone el determinar lo que la ficha de plástico supone para el chimpancé. Señala que para que podamos considerar que el chimpancé utiliza las fichas como palabras, ha de mostrar tres cosas. El chimpancé ha de ser capaz de utilizar la ficha para pedir el referente que ha sido asociado a ella. Debe ser capaz de elegir la ficha cuando se le pide que nombre el referente. $Y$ ha de ser capaz de describir, de alguna manera, el referente cuando sólo esté presente la ficha.

Aunque en nuestra opinión esta lista es incompleta, al menos se reconoce que la simple asociación entre símbolo y referente no es razón suficiente para que el experimentador afirme que una respuesta equivale a una palabra. Sin embargo, hay razones para dudar seriamente de la forma en que se comprobó el que efectivamente Sarah poseía las tres habilidades reseñadas. Por ejemplo, Premack no distingue claramente desde el punto de vista del procedimiento entre nombrar la comida y pedir la comida. Para que se considere que el animal es capaz de nombrar la comida éste ha de ser capaz de elegir el símbolo correspondiente, sin que se le permita, a continuación, consumir la comida como premio- de no ser así no se puede distinguir entre nombrar la comida y pedir comida. Al parecer se le permitía a Sarah comerse el objeto nombrado, siempre que éste era comestible. Esa distinción en el procedimiento es muy relevante, ya que el que el chimpancé tenga la capacidad de pedir no implica que tenga la capacidad de nombrar.

Se aseguraba que Sarah era capaz de construir una gran cantidad de frases, pero lo único que se le exigía en realidad era que reconstruyera secuencias de símbolos ya aprendidas. Por ejemplo, en una frase tal que Maria dar Sarah manzana, la palabras Maria, dar y Sarah no variaban a lo largo de la sesión de entrenamiento. Por tanto, la verdadera tarea de Sarah consistía en elegir la ficha asociada con la comida que le presentaba el experimentador. Esto es en esencia un ejercicio de asociación de nombres, en el que la elección se hacía entre dos símbolos, y por tanto, con una probabilidad de acierto del 50 por 100 en cada ocasión. Dado que Sarah no necesitaba poseer habilidades sintácticas ni representacionales para elegir adecuadamente los cuatro símbolos a los que Premack había asignado los contenidos «María dar Sara manzana», la explicación más sencilla es suponer que Sara combinaba capacidades de ordenación y asociación a la hora de producir tales frases.

A partir de los artículos de Premack (1971, 1976), resulta difícil determinar la amplitud del vocabulario de Sarah, el número de elementos de su vocabulario que habían sido comprobados en condiciones adecuadamente controladas y qué capacidades semánticas. En los casos en que es posible reconstruir exactamente el procedimiento utilizado con Sarah resulta dudoso hasta qué punto «Premack ha interpretado correctamente la forma en que sus sujetos perciben los símbolos y la secuencia de símbolos que se les exige utilizars (Terrace, 1979, p. 166).

La capacidad de Sarah de describir el referente de una ficha de plástico cuando esta se le presenta se comprobó sólo con dos elementos del vocabulario, manzana y caramelo. El método básico utilizado por Premack para estas comprobaciones fue el de aparear-con-muestra. Inicialmente la muestra era una manzana de verdad y Sarah tenía que elegir, entre dos manihas de co- 
lor, el que más se parecía al de la manzana. También se hicieron pruebas de elección con formas, con figuras rojas, que tenían o no el arabito de la manzana y con otros formas, asimismo, con y sin «rabito - un cuadrado con «rabito» y un círculo sin rabito (este último grupo era ambiguo y las respuestas de Sarah también fueron ambiguas). En los tres casos no ambiguos Sarah eligió el elemento correcto. A continuación, se sustituía la manzana real por el símbolo que en el sistema diseñado por Premack representaba manzana (en concreto era un triángulo azul), pidiéndosele a Sarah que repitiera las pruebas de aparear-con-muestra, pero ahora sólo en los casos no ambiguos.

Pero, tal como ya hemos indicado en otro lugar, Sarah no necesitaba en el segundo caso saber que el triángulo azul representaba a la «manzana» para responder correctamente (Savage-Rumbaugh et al. 1978b). Le bastaría con recordar las elecciones precedentes con las mismas figuras, pero con la manzana presente. Dado que ninguna de la figuras en ningún aspecto parecía un triángulo azul (la «palabra manzana), no había posibilidad de que eligiera algo parecido a lo que tenía delante (el triángulo azul). Siendo así, y aunque no considerase que el triángulo azul representara a la manzana, al presentársele por segunda vez las mismas alternativas que en el caso anterior, la elección más razonable y conservadora desde la posición de Sarah tendría que ser elegir el mismo elemento que había elegido previamente en presencia de la manzana real. Es fácil para los chimpancés recordar tres de estas elecciones (SavageRumbaugh et al. 1978b).

Todavía más, Premack no consiguió demostrar que Sarah fuese capaz de utilizar los símbolos de manzana y caramelo cuando se le ofrecía un amplio abanico de posibilidades, ni que fuese capaz de pedir la comida cuando estaba presente, ni nombrar la comida cuando se le pedía que lo hiciera sin que se le diera a comer, ni seleccionar estos alimentos entre otros y dárselos al experimentador como respuesta al uso del símbolo por parte de éste. En resumen, Premack no presentó evidencia que apoyase la pretensión de que Sarah poseía una comprensión semántica de las palabras amanzanas o acaramelo».

Premack (1976) reconoce que los resultados de Sarah en esta prueban pueden ser explicados en base a la tarea de aparear-con-muestra y al recuerdo, pero añade que, posteriormente en otras pruebas, Sarah fue capaz de elegir correctamente los símbolos que representaban a aredondos y «rojos en los pares correspondientes, en lugar de elegir los objetos que eran redondos y rojos. Sin embargo, no se puede decir que quedara claramente establecida la capacidad de Sarah para ac- tuar adecuadamente ante los símbolos que representan «redondo y «rojo». En su última prueba de elección entre pares con «nombres» de colores, Sarah acertaba en un 76 por 100 de los casos y en la única prueba con los anombres» redondo y cuadrado de la que se dan datos su rendimiento era del 69 por 100 . En ninguno de los dos casos se obtuvieron los datos bajo unas condiciones de control que asegurasen la ausencia de pistas extraexperimentales. El propio Premack (1976) señala que alos nombres propios le resultaban a $\mathrm{Sa}$ rah mucho más difíciles que cualquier otro conjunto de elementos léxicos» (p. 185). Parece bastante gratuito el conceder a Sarah la capacidad de elegir los símbolos «redondo» $y$ «rojo» en respuesta a la palabra emanzana», cuando de hecho no era capaz de elegirlos consistentemente ante la presencia real de cosas redondas o rojas.

Una atenta revisión de todos los informes del trabajo inicial de los Gardner con Washoe, permite comprobar que sólo se realizaron dos pruebas controladas sobre la capacidad de Washoe; en concreto, dos pruebas sobre la capacidad de «nombrar», que al parecer se hicieron ambas con un mismo grupo de 33 términos, aunque nunca se especifica cuáles fueron exactamente tales términos. Los resultados de Washoe en tales prue. bas arrojaron un 53 por 100 y 71 por 100 de aciertos, respectivamente.

Antes de que dejase Nevada y fuese llevada a Oklahoma los informes decían que Washoe era capaz de nombrar 132 cosas (acciones, objetos y estados); sin embargo, dado que sólo 33 de tales nombres habían sido comprobados de forma controlada, no queda claro hasta qué punto Washoe utilizaba adecuadamente los 99 signos restantes. El resto de los datos que se ofrecen del proyecto Washoe son básicamente observaciones, interpretaciones y podrían estar contaminados por pistas extraexperimentales (Seidenberg y Petitto, 1979).

A todo lo largo del trabajo de los Gardner se mantiene la presuposición - poco feliz - de que producción significa comprensión. Digamos de nuevo que mientras tal suposición pueda ser cierta en el caso de un niño humano normal no es aplicable a los chimpancés (Savage-Rumbaugh, 1979) o a seres humanos especiales, tales como los retrasados mentales o con lesión cerebral, los autistas o los que se han desarrollado en un medio extraordinariamente pobre (Curtiss 1977).

Los Gardner no hacen ningún intento de separar el contexto no lingüístico del lingüístico. De hecho, las pistas tradicionalmente consideradas como no lingüísticas, tales como señalar los objetos o simular acciones, son consideradas como signos y tratados como elementos de comunicación lingüística. Los gestos, no simbólicos, de señalar son traducidos por «tú», «yo», «ir», 


\section{Estudios}

«allí, «estes, seses, «miras, aescuchas y atiempox. Los gestos direccionales, no simbólicos, hechos con toda la mano se traducen por adame», aven», avetes y amío (Petitto y Seidenberg, 1979; Seidenberg y Pettito, 1979). Aunque efectivamente es posible que Washoe utilizara gestos no lingüísticos para llamar la atención sobre «este» objeto, o sobre «aquella» persona, tales gestos no pueden ser traducido por la palabras este y aquella.

Los problemas que se derivan de la posibilidad de que el experimento o el contexto estén suministrando pistas a los simios y que eran imputables a los primeros informes sobre los trabajos con lenguajes de signos, siguen sin ser tenidos en cuenta en los siguientes informes (Gardner y Gardner, 1978a). Resulta bastante fácil darles pistas a los chimpancés, incluso de forma inconsciente. Algunos críticos de estos trabajos han llegado a sugerir que sus resultados podrían catalogarse junto a los de Hans el Listo (Sebeok y Umiker-Sbeok, 1979). Hans el Listo era un caballo que a finales del siglo pasado desconcertó a los científicos por su aparente capacidad para contar, resolver problemas aritméticos y contestar algunas otras preguntas. Eventualmente, se descubrió que lo que ocurría era que detectaba ciertas inadvertidas pistas que le suministraba su entrenador o las personas que lo examinaban. Pero compararlo con el lenguaje de los simios, aunque sirve para subrayar lo sutiles que pueden llegar a ser las pistas, es una simplificación excesiva de la cuestión. Lo único que hacía Hans el Listo era golpear el suelo con una pata delantera y las únicas pistas que necesitaba eran las de «empezar» y «parar». En cambio, las conductas de los chimpancés que estamos discutiendo -aún en el caso de que no tuviesen significado alguno- son demasiado complejas como para ser controladas por pistas del tipo de «empieza» y stermina».

No obstante, es posible que se esté dando un sistema de pistas más complejo y sofisticado. En cada situación, tanto el chimpancé como el experimentador saben cual es el subconjunto apropiado, aunque el chimpancé no sabe exactamente qué signo concreto ha de hacer. Siendo así, el chimpancé ejecutará de forma dubitativa, dispersa, repetitiva o compulsiva, algunos movimientos de manos, mientras mira atentamente a la cara del experimentador. Cuando alguien trata con mucho interés de enseñar un signo a un chimpancé resulta muy difícil no mostrar cierto disgusto o alegría según que el animal empiece a hacerlo mal o bien, respectivamente. Es posible, por tanto, que le estemos dando una pista al chimpancé al mostrar nuestra aprobación si hace el signo correcto o elige el símbolo adecuado. Dado que el chimpancé no posee una inclina- ción propia hacia el aprendizaje referencial es fácil que recurra a la ayuda del experimentador y cuanto más intente el experimentador dejar actuar al animal, más tratará éste de fijarse en las más mínimas pistas.

Nuestras propias ideas respecto al uso de simbolos han resultado considerablemente modificadas a lo largo de los siete años del experimento Yerkes sobre lenguaje, por ello los puntos de vista que sostenemos aquí contradicen algunas de las cosas que anteriormente sosteníamos. Los datos de que disponemos ahora son mucho más amplios que los iniciales: hemos trabajado con cinco chimpancés más y con nueve niños retrasados mentales. Hemos comprobado que la capacidad de producción no puede ser tomada como el único índice de la existencia de una capacidad de manejar y comprender el lenguaje y hemos aprendido a fijarnos en la conducta global de los chimpancés en lugar de centrarse exclusivamente en las conductas interesantes o novedosas. Asimismo, hemos descubierto que mientras que es relativamente fácil, tanto para los chimpancés como para los retrasados mentales, desarrollar conductas que superficialmente se asemejan a las conductas lingüísticas, tesulta muy difícil para ellos alcanzar la función simbólica y comunicativa y su recíproca función receptiva que son, en definitiva, las que constituyen la esencia del lenguaje. A continuación, presentamos una crítica de las producciones lingüísticas de Lana (Rumbaugh, 1977), en la misma línea de lo que se ha criticado los restantes proyectos de lenguaje.

En los informes sobre Lana se decía que ésta poseía un vocabulario de 75 elementos, pero sólo se presentan datos de pruebas controladas con 21 de ellos (Rumbaugh, 1977). El rendimiento de Lana en estos elementos fue del 79,6 por 100. En algunas pruebas se le presentaban a $\mathrm{La}$ na todos los símbolos; en otras sólo se presentaban dos, por ejemplo más y menos. En todas estas situaciones lo único que se exigía de Lana era la capacidad de etiquetar. Muchas de las frases de Lana, al igual que las de Sarah, consistían en rellenar el espacio en blanco de cadenas redundantes. Para evitar errores, estas frases se consideraron como frases ahechass, y no se dedujo de ellas que Lana entendiese cada uno de los elementos de la frase por separado. Sin embargo, se informó que en otros muchos casos Lana había producido cadenas totalmente nuevas que resultaban adecuadas tanto desde el punto de vista sintáctico como pragmático, por ejemplo: ?tú mover coliflor fuera máquina o ?túu mover máquina fuera cuarto (Gill, 1977). A partir de frases de este tipo y otras concluimos que Lana estaba trabajando a nivel lingüístico y que poseía «significados conceptuales» para casi todas, 
si no todas, estas frases (Rumbaugh y Gill, 1977). Ciertamente la capacidad representacional de Lana no fue directamente comprobada, y dado que la mayoría de las nuevas combinaciones, que resultaron interesantes y adecuadas, ocurrieron durante la relación cara a cara entre Tim - un entrenador- y Lana, no es posible excluir totalmente la posibilidad de que hayan existido pistas involuntarias. No obstante, pensamos que el hecho de que Lana fuese capaz de utilizar combinaciones tan nuevas implica que posee capacidad representacional.

Al principio, estas combinaciones se daban con poca frecuencia y nos inclinábamos a pensar que se trataba de intentos, por parte de Lana, de expresar deseos cuya expresión lingüistica aún no le había sido enseñada. A medida que fueron siendo más abundantes (cosa que se debió probablemente a que se contestaban con entusiasmo y alegría, por parte del experimentador), pudimos llegar a obtener un perfil revelador acerca de estas nuevas producciones de Lana. La Tabla 1 muestra el conjunto de frases hechas que utilizó Lana - completas o con omisionesa lo largo de un período de dos meses, enero y febrero de 1979; en la Tabla 2 se muestran las 174 nuevas producciones formadas por Lana durante el mismo período de tiempo. Queda claro que muchas de las nuevas combinaciones de La- na están incluidas en la estructura de una o más de las frases hechas, y unas pocas de las nuevas combinaciones de cinco a ocho palabras parecían reflejar una falta de comprensión semántica de varios elementos de la cadena, o del significado de su colocación con respecto al resto de la cadena. El colocar las nuevas producciones en el contexto de todas las producciones, elude en parte el problema de las descripciones anecdóticas y aisladas que caracterizan muchos informes sobre el lenguaje en simios. Nótese que pese a que las nuevas producciones suponen sólo un 6 por 100 del total de producciones, suelen ser semánticamente correctas y, por tanto, el hablante normal del inglés tenderá a considerarlas como frases con un sentido. Dado que la mayoría de ellas son peticiones de comida, cosquillas o cambios de sitio (cosas que Lana siempre quería), el oyente inglés de tales peticiones no tendría razones para pensar que tales frases no tenían significado para Lana. Pero el hecho es que no son tanto estas frases nuevas en sí, sino la ausencia de abundantes combinaciones sin sentido lo que sugiere que Lana tenía algún nivel de comprensión de tales símbolos y de la forma en que habían de ser combinados.

No hay manera de demostrar definitivamente que Washoe, Sarah, Lana, Koko o Nim utilizaban símbolos de forma representantiva. Pero en-

Tabla 1. Esquemas de frases hechas utilizados por el chimpancé Lana durante un período de dos meses.

Formato *

Interrogación $\begin{aligned} & \text { pronombre } \\ & \text { o nombre }\end{aligned}$ da $\begin{aligned} & \text { nombre de objeto, nombre de } \\ & \text { comida o nombre propio }\end{aligned}$ a Lana en cuarto

(?Tú dar pan a Lana en cuarto)

Por-favor, máquina dar un poco de nombre de comida (por-favor máquina dar un poco de pan)

Interrogación tú hacer $\left[\begin{array}{l}\text { puerta o } \\ \text { ventana }\end{array}\right] \begin{aligned} & \text { abrir o } \\ & \text { cerrar }\end{aligned}$

(?Tú hacer puerta abrir)

Intertogación $\begin{aligned} & \text { nombre propio } \\ & \text { o pronombre }\end{aligned}$ mover $\begin{aligned} & \text { dentro } \\ & \text { o fuera }\end{aligned}$ cuarto

(?Lana mover fuera cuarto)

Interrogación $\begin{aligned} & \text { nombre propio } \\ & \text { o pronombre }\end{aligned}\left[\begin{array}{c}\text { cosquillas } \\ \text { o caricias }\end{array}\left[\begin{array}{c}\text { nombre propio } \\ \text { o pronombre }\end{array}\right.\right.$

(?Tú cosquillas Lana)

$\begin{aligned} & \text { nombre común nombre este color } \\ & \text { o propio }\end{aligned}$
(Zapato nombre de-este rojo)

Símbolo aislado

* Los elementos variables se encierran en un cuadro; se añade un ejemplo a cada caso.

* Número total de veces que utilizó las distintas variantes de esquema de frase, incluyendo las versiones incompletas.
Total * 


\section{Estudios}

Tabla 2. Frases inéditas utilizadas por Lana en un período de dos meses.

$$
\text { Frase } \begin{gathered}
\mathrm{N} \cdot{ }^{\circ} \\
\text { de apariciones }
\end{gathered}
$$

Interrogación tu nombre esto

Interrogación dar bebida esta

Nombre este zapato

Nombre esta taza

Interrogación beber esto

Fuera por-favor

Interrogación tu dar pastel-de-judías cerrado abierto

Por-favor leche fuera cuarto

Interrogación tu cosquillas-Lana ir

Esta pelota

Interrogación tu cosquillas-Lana junto cuarto

Quiero sí

Interrogación tu cosquillas-Lana dentro cuarto

Interrogación tu cosquillas-Lana en cuarto

Interrogación tu dar Columbus-en Lana cuarto

Tu abrir

Interrogación tu cosquillas-Lana a Lana

Interrogación tu cosquillas-Lana a Lana junto cuarto

Fuera cuarto

Por-favor leche cuarto

Fuera cuarto si

A fuera cuarto

Interrogación tu dar leche-abrir

Interrogación tu dar leche-cerrado abierto

Interrogación tu dar esta naranja beber

Interrogación tu dar esto a-Lana en cuarto

Interrogación tu abrir

Sí dinero

Interrogación Lana tu fuera-cuarto
Dar fuera cuarto 2

Abrir sí 2

Interrogación tu dar Lana-Columbus 2

Hacer ventana abrir máquina 2

Leche fuera

Por-favor leche fuera

Por-favor hacer máquina musica-ventana abrir

Interrogación tu cosquillas Lana por-

favor

Ir por-favor

Si fuera cuarto

Por-favor fuera cuarto

Por-favor tu

Mover Columbus

Fuente nombre es flan

Por-favor máquina arreglar

Interrogación tu dar ir

Interrogación Lana Columbus

Cosquillas interrogación

Beber sí

Mano ojo pie

Ventana panel

Dar Lana comida

Interrogación tu dar Lana jugo

Intertogación tu dar pan a máquina

Naranja cocina

Interrogación Lana en cuarto comer sí Interrogación tu dar plátano a Lana

en máquina fuera cuarto

Interrogación tu dar jugo a Lana en

taza fuera cuarto

Interrogación tu dar pan Lana

Interrogación Lana dar pan a cuarto

Dar Lana leche

Interrogación tu dar Lana
2
2
2 tonces, si tales simbolos no representan objetos, hechos y relaciones para los simios, ¿cómo ha sido posible que hayan aprendido a utilizarlos de una forma que parece apropiada en muchas tareas difíciles? También debemos preguntarnos cómo se puede evaluar de forma fiable el componente referencial, y tenemos que buscar medios para comparar las habilidades en los distintos proyectos y en las distintas modalidades de símbolos.

\section{EL APRENDIZAJE DEL LENGUAJE MEDIANTE EL «SI-ENTONCES»}

A menudo los investigadores no consiguen especificar qué es exactamente lo que se exige de un chimpancé cuando se le hace aprender un símbolo dado, pese a que es precisamente esta exigencia y las contingencias de refuerzo asociadas lo que representa el conocimiento del mun- do real que el animal tiene relacionado con el símbolo y su uso. Si el chimpancé adquiriese el lenguaje sin necesidad de un entrenamiento intensivo (tal como a veces parece suponerse) entonces no podríamos saber, sobre cómo y por qué se produce el comportamiento simbólico en los chimpancés, más de lo que sabemos del caso de los niños humanos. Pero en el caso de los chimpancés es necesaria una enorme cantidad de entrenamiento (tal como queda reflejado en los presupuestos económicos de todos los proyectos del lenguaje en simios) y por ello puede especificarse las contingencias contextuales exactas asociadas con el aprendizaje de cada palabra.

Todos los investigadores en el área del lenguaje en simios han utilizado técnicas de enseñanza muy similares, aunque en los informes de los distintos proyectos se tiende a enfatizar diferencias en modalidad, criterios, situación social, etc. El paradigma de entrenamiento básico consiste en una cadena de condicionamientos de discri- 
Tabla 3. Ejemplos de contingencias secuenciales que incluyen los paradigmas báscos de entrenamiento de simios en el lenguaje.

\section{Pauta *}

CHIMP.

1. Conducta no verbal del chimp. indicado que desea que el humano haga algo en concreto.

HUMANO 2. El humano ejecuta un acto o se ríe de actos en relación a lo que el chimp. ha indicado que desea.

\section{CHIMP. 3. El chimp. hace un símbolo.}

HUMANO 4. El humano hace lo que se le pide.
Exp. de Gardner

1. El chimp. se acerca a la puerta e intenta abrirla haciendo gestos de que quiere que el humano la habra.

2. El humano se acerca también a la puerta, señala el picaporte, señala hacia fuera, abre un poco la puerta y la cierra - moviendo las manos de juntas a separadas en forma parecida al signo abrit en ASL.

3. El chimp. hace el signo abrir.

4. El humano abre la puerta y permite salir al chimp.
Exp. de Premack

1. Sarah está intentando conseguir un dulce y otras golosinas (Sarah quiere que el humano le de la comida).

2. El humano prepara y ofrece a Sarah una presentación que incluye una manzana $y$ varias fichas de plástico de colores y formas diferentes.

3. Sarah elige una ficha de entre dos.

4. El experimentador le da a Sarah una manzana.
Exp. de Rumbaugh

1. Lana mira o señala un sugus o el dispensador de sugus.

2. El experimentador pone un su. gus en el dispensador, en su caja receptora que está fuera de la habitación.

3. Lana pulsa una serie de símbolos, algunos familiares y otros no.

4. Lana se puede comer el sugus dado que el experimentador ha pro. gramado el dispensador para que responda automáticamente.

- Cada acción sólo tiene lugar si ha ocurrido antes la precedente. 


\section{Estudios}

minación secuenciales e interconectados: Si ocurren las condiciones $a$ y $b$, entonces elige el símbolo $x$. En los casos de Lana y Washoe los chimpancés respondian a acciones y gestos indicativos realizados por seres humanos, en lugar de un medio estimular inanimado. Esto supone que las secuencias de contingencias «si-entonces» son de naturaleza interindividual, de manera que las respuestas de un individuo es el estímulo de la subsiguiente conducta del segundo individuo (Tabla 3).

Es importante señalar que en el caso del entrenamiento con el ASL, el chimpancé no tiene que vérselas a lo largo del entrenamiento con niveles significativos de similaridad contextual. Un experimentador humano puesto de pie junto a la puerta y señalando hacia afuera es muy dife. rente del mismo experimentador cogiendo al chimpancé en su regazo, poniendo cara de jugar y haciendo gestos anticipatorios de hacerle cosquillas. Y por tanto, aprender el signo de «cosquillas» en un contexto y el signo *abrir» en el otro ha de ser relativamente fácil, dado el alto grado de discriminabilidad propio de estas dos situaciones. Diferencias contextuales tan marcadas se hacen cada vez más importantes al aumentar el repertorio de signos, dado que cuanto mayor sea el número de pistas discriminativas de una situación más fácil se le hace al chimpancé recordar el signo adecuado.

Una revisión de la descripción que hacen los Gardner del uso que hacía Washoe de los signos, así como de los errores y de las combinaciones, apoyan esta conclusión. Por ejemplo, los Gardner señalan que el signo uberida» "puede ser elicitado por s la aparición de cortes o rozaduras; el signo "cubrir» aparece en «juegos en los que Washoe se escondex; el signo "girar» surge cuando «una persona... da vueltas bailando», y así otros muchos casos (p. 147-57). Todos estos estímulos constituyen situaciones plagadas de pistas distintivas. Señalan también los Gardner que los errores tienden a ocurrir en egrupos significativos». Por ejemplo, el signo prisa aparece «mientras se prepara la comida, cuando el experimentador manipula un alimento que Washoe deseas; el signo dulce aparece cuando el experimentador manipula una gaseosa u otra bebida deseable». En ambos casos, el experimentador tiene un alimento altamente deseable, que Washoe desea ingerir. Bajo tales circunstancias pueden aparecer combinaciones tales como aprisa dulce bebida» (p. 167), debido a esta destacable pista.

La distintividad contextual que existe en el trabajo de los Gardner con Washoe está ausente, de forma intencional, en el trabajo de Premack con Sarah y por tanto la tarea básica de aprendizaje que exige Premak difiere en varios aspectos de la de los Gardner. En primer lugar, en el paradigma utilizado por Premack se le pide a Sarah que responda (mediante la elección de símbolos), no a los actos o acciones de seres humanos, sino sólo a la aparición de unos objetos concretos. Aunque a primera vista esto puede parecer una distinción sin importancia, en realidad se trata de algo clave en todo el proceso de comunicación simbólica interindividual o lenguaje. La puerta, que está siempre presente, sólo se convierte en parte del contexto comunicativo cuando las personas o el chimpancé señalan el picaporte, miran a través de la mirilla de la puerta, señalan hacia fuera... etc. En el caso de Sarah, en cambio, el estímulo no está normalmente presente excepto cuando se le somete al ensayo de selección de ficha. La pista relevante para la selección de una determinada ficha es la presentación de una configuración concreta de fichas, y no la conducta gestual del experimentador humano.

Aunque es cierto que las diferentes conductas del experimentador humano y los cambios en el medio (tales como la presencia de una manzana) pueden ambos ser interpretados simplemente como estímulos discriminativos, este enfoque deja de lado la cuestión central. La discriminación ha de ser entre las conductas de los individuos si han de ser percibidos por los participantes como comunicativas. En última instancia es razonable suponer que el chimpancé Washoe podía percibir los determinantes de su elección de signo como la conducta del experimentador que estaba de pie junto a la puerta y no la presencia estática o la aparición de una manzana y fichas de plástico en el tablero de presentaciones. La elección de símbolos a cargo de Sarah, sin embargo, se percibiría como dependiente de una situación externa inanimada.

¿Importa verdaderamente esta diferencia? Si la cuestión es el lenguaje, la respuesta es sí, importa; ya que no tiene sentido para un organismo el utilizar símbolos para comunicarse con los objetos inanimados que le rodean. Incluso en el caso de que un gesto o símbolo no represente a ningún elemento de los que se incluyen en inglés, tendrá que ser considerado como capaz de alterar funcionalmente la conducta de otro ser animado para que el que lo utiliza lo considere comunicativo. Esta es la razón por la que sujetos humanos competentes lingüísticamente a los que se les presentó la tarea de Sarahi no se dieron cuenta de que las fichas de plástico funcionaban como indicadores lingüísticos (Premarck, 1978).

Otra diferencia fundamental en el paradigma de entrenamiento de Premack es que la conducta de la propia Sarah jugaba un papel relativamente secundario a la hora de determinar el tipo de discriminaciones condicionadas que sucesiva- 
mente se iban a presentar y por supuesto respecto de si una determinada discriminación se presentaba o no. En cambio, en el caso de Washoe esta podía hacer intentos de salir, de hacer cosquillas al experimentador, de coger comida, etc., permitiendo así que el experimentador dedujese que a Washoe le gustaría hacer tal cosa y pudiese organizar la situación al objeto de que apareciese el signo correspondiente. Sarah no podía hacer nada de esto. Ella simplemente estaba en su jaula y cuando el experimentador le presentaba un problema y ella daba la respuesta correcta recibía algo de comer. Por tanto, incluso al nivel no verbal se le impedía comunicar sus deseos de cosquillas o de salir, dado que se evitaba que realizara esas conductas como señal de su deseo de realizar tales actividades.

La tercera diferencia fundamental entre los paradigmas de discriminación utilizados por los Gardner y por Premack se refiere al número de respuestas alternativas. Teóricamente, Washoe, que estaba en libertad para hacer cualquier gesto con las manos, tenía siempre todos los signos conocidos como posibilidades para elegir, a la hora de dar una respuesta. Sin embargo, generalmente Sarah tenía que elegir entre dos alternativas no redundantes (si-no, igual-diferente, redondo-cuadrado..., etc.). Probablemente Washoe no recordaría todos los signos que conocía todo el tiempo, sobre todo porque el criterio de adquisición de signos no era muy seguro, peto es razonable suponer que en cualquier ocasión dada, el número de sus respuestas alternativas era considerablemente mayor que dos. El número limitado de alternativas que se le presentaban a Sarah harían innecesario que ella organizase sus respuestas potenciales en forma sistemática. La elección de los símbolos respuesta de la categoría en cuestión (forma, comestible, color) le venía dada. Siendo así, los errores dentro de una categoría - por ejemplo confundir rojo y azul - no reflejaban ni un esquema de categorización interno - tal como acolorn- ni respuestas erróneas a pistas discriminativas similares. Unicamente reflejan las elecciones limitadas de que dispone Sarah. Dado que Sarah siempre trabajaba en una única tarea en cada situación de prueba es difícil imaginar cómo pudo haber llegado a formar los conceptos semánticos de categoría que Premack le atribuye.

En resumen, las discriminaciones sucesivas de Sarah suponen que: primero, no hay elección o utilización espontánea de símbolos; segundo, no hay indicadores gestuales (tales como señalar), que permitan una coordinación entre la atención del simio y del experimentador; tercero, sólo existen presentaciones de símbolos simples y estructurados; cuarto, sólo hay respuestas de elección dicotómica, y quinto, no hay otro pre- mio que comida. Las discriminaciones sucesivas de Washoe incluyen: primero, frecuente uso y elección espontánea de símbolos; segundo, coordinación constante de la atención mediante gestos no verbales; tercero, múltiples situaciones complejas y no estructuradas; cuarto, numerosas posibilidades de respuestas, y quinto, premios de diversa naturaleza.

¿Y en el caso de Lana? Pues se puede decir que, con unas mínimas modificaciones, es aplicable a su adquisición inicial de símbolos el mismo esquema de los proyectos que acabamos de analizar. En un principio, al igual que con Sarah, la situación de entrenamiento se organizaba alrededor de la adquisición de comida. Pero al igual que las puertas estaban presentes siempre en el caso de Washoe, los varios dispensadores de comida estaban siempre presentes en el caso de Lana. La conducta no verbal de Lana, al igual que la de Washoe, comunicaba el mensaje básico- el deseo de Lana de recibir un jugo, un sugus, cosquillas... etc. Al igual que con Sarah, a Lana se le hacía elegir (no hacer) un símbolo, pero como Washoe, su elección del símbolo correcto (o del conjunto de símbolos correctos) se hacía de entre todos los símbolos que conocía y no de entre dos o tres. Pero a diferencia de Washoe y de Sarah, Lana utilizaba símbolos que se construíar: mediante combinación de uno, dos o más de entre nueve elementos gráficos, de la misma manera que las palabras en inglés se escriben mediante combinación de uno, dos o más de los veintiséis elementos del alfabeto. Por tanto, Lana, a diferencia de Washoe o Sarah, se veía forzada a fijarse en cada elemento del complejo estimular, y no sólo en la impresión de conjunto.

A continuación del entrenamiento inicial con Sugus y jugos se le enseñó otras discriminaciones condicionadas que permitían a Lana salir, ver películas, ser paseada, recibir cosquillas y acicalamientos, etc. A continuación se enseñó a Lana una serie de tareas más estructuradas, tales como decir los nombres y colores de los objetos. En estos entrenamientos sólo variaban los objetos o sus colores, permaneciendo constante el resto de la tarea de entrenamiento, incluido el panel de respuestas. Esta tarea era igual a la que típicamente se le presentaba a Sarah, a excepción de dos cosas: Se le pedía a Lana que dijese el color 0 el nombre, o ambas cosas; y todos los colores y lexigramas nominales estaban presentes, asi como todos los objetos reales. El objeto que debía ser descrito en cada momento era señalado por el experimentador mediante gestos.

Por tanto, el paradigma de entrenamiento básico de Lana puede decirse en resumen que su. ponía: primero, frecuente elección y uso espontáneo de los símbolos (como Washoe); segundo, 


\section{Estudios}

la utilización de indicadores gestuales para coordinar la atención del simio y del experimentador; tercero, tanto situaciones ambientales múltiples complejas y desestructuradas (al estilo de Washoe), como presentaciones de estímulos simples y estructurados (al estilo de Sarah); cuarto, numerosas posibilidades de elección de respuestas; y quinto, una amplia gama de recompensas (como Washoe). A diferencia tanto de Washoe como de Sarah las posibles respuestas de Lana se componían de elementos abstractos recombinados. Su ambiente social no era ni tan variado como el de Washoe ni tan restringido como el de Sarah y a diferencia de ambas Lana podía utilizar la producción de símbolos para producir cambios ambientales con independencia de que estuviese presente o no un ser humano.

\section{COMUNICACION PROTOLINGUISTICA}

En algún momento de su entrenamiento tanto Lana como Washoe comenzaron a utilizar su sistema de comunicación para controlar y regular la conducta de sus entrenadores humanos. En otras palabras, se invirtió el orden del paradigma de condicionamiento de discriminación antes descrito y, por tanto, no era siempre el ser humano el que preparaba las contingencias para elicitar el signo o lexigrama. El simio comenzó a preparar las contingencias y a producir los signos o lexigramas al objeto de establecer una situación predecible en la que el experimentador daría la comida, permitiría la salida o daría lugar a otros sucesos deseables. En este punto emerge la comunicación intencional prelingüística. Una emergencia similar de la intención comunicativa se ha encontrado en niños alrrededor de los nueves meses de vida (Clark, 1978). Es importante señalar que no se mencionan conductas de este tipo en el caso de Sarah.

Según Bates (1976) y Clark (1978), la comunicación internacional prelingüistica aparece en los niños humanos cuando las acciones se modifican y ritualizan, de manera que se pueden utilizar como elementos de comunicación. Esto permite al niño actuar sobre su medio de forma indirecta mediante las acciones de otros guiadas por sus gestos. Hasta este momento el niño sólo puede actuar sobre el medio de forma directa, a través de sus propias acciones. A medida que esta interacción interindividual (intermental en la terminología de Clark) y estructurada se hace más ordenada y el niño se va creando expectativas respecto de su propio papel y el de los demás; en tales intercambios el niño pasa del reino de la pasividad respondiente al de la comunicación intencional.
En el estudio de Clark sobre el dar y el coger entre madre e hijo, este autor encontró que al principio los niños levantan las manos sólo cuando van a coger un objeto que la madre está dándoles. Pero estas interacciones de dar y coger se hacen más predecibles por ambas partes, se ritualizan, de manera que la acción de tratar de coger por parte del niño se anticipa a la acción de ofrecer de la madre. Cuando ocurre esto, las acciones dejan de ser simples respuestas y comienzan a servir como comunicadores funcionales capaces de dirigir y controlar las acciones de los otros.

Con esta habilidad recién adquirida el niño humano o el chimpacé desarrolla una creciente conciencia de la función de los gestos y las miradas en la coordinación de las conductas interindividuales. Mediante repetidos intercambios el rol del chimpancé se va definiendo como el de seleccionar un signo o lexigrama mientras que el rol del experimentador humano se va definiendo como el de realizar la acción asociada, tal como abrir la puerta, dar comida o hacer cosquillas. Por tanto, el lexigrama o signo se convierte en la conducta que tiene que realizar el chimpancé cuando quiere que el ser humano lleve a cabo un cierto acto. La intención y la expectativa es evidente dado que cuando al ser humano no responde de manera adecuada, el signo o lexigrama así como los actos asociados se repiten mientras se trata de conseguir un contacto visual. Lo mismo se puede decir del niño cuando levanta sus bracitos pidiendo algo: el gesto se mantiene de forma insistente si la madre no hace caso. Antes simplemente se hubiese dejado de hacer el gesto.

Gestos como estos no sirven verdaderamente para transmitir información sobre lo que se quiere que ocurra, sino más bien informan de que quien ha iniciado el gesto desea que algo ocurra, siendo ese algo lo que resulta obvio dado el contexto. Por tanto, si Washoe se acerca a la puerta y trata de abrirla y luego hace el signo abrir (o al revés), la acción de intentar abrir define el significado del gesto. El signo de abrir (un movimiento como de tratar de abrir) es el gesto comunicativo que, mediante repetidas secuencias de acción de este tipo se convierte en una parte del papel de Washoe (o su parte en el juego) en este contexto. El acto de abrir la puerta en respuesta al signo es el papel del experimentador humano. Sin embargo, el signo abrir ni se refiere a como esté la puerta, ni puede ser utilizado para comunicar información sobre la puerta, una vez que el acto de abrir la puerta ha sido realizado. El signo abrir por lo tanto no tiene función representacional o referencial fuera de ese contexto. No aisla conceptualmente una acción permitiendo 
utilizarla en actividades cognitivas arbitrarias, tal como las palabras acaban haciéndolo en el caso de los niños humanos (Pylyshyn, 1977).

El vocabulario de Washoe puede considerarse constituido por dos tipos de signos, los que funcionan como comunicadores prelingüisticos ligados a un contexto (abrir, hacercosquillas, venir-ven, dame..., etc.), y los que funcionan como asociaciones aprendidas ente una cosa y un signo (sombrero, flor, pantalones, zapato..., etc.). Dado que los Gardner no distinguen entre la habilidad para etiquetar ítems o cosas, tales como flores y plantas, y la habilidad para señalar una necesidad tal como «abrir», cuando se necesita que se abra una puerta, presuponen que Washoe puede utilizar todos sus signos tanto para realizar las funciones semánticas de etiquetar como las de solicitar. Sin embargo, los signos utilizados para etiquetar (plantas, flores, zapatos) no aparecen normalmente en peticiones espontáneas.

Los Gardner (1971) señalan que los signos más comunmente utilizados por Washoe para hacer peticiones expontáneas son las siguientes: ven-däme, por-favor tū, ir, yo, rápido, más, arriba, abrir, fuera, dentro y comida. Todos estos signos son los propios de las dos situaciones de pedir más comunes, comer o cambiar de lugar. Entre estos signos de peticiones espontáneas no hay etiquetas de objetos específicos. Aunque comida podría ser considerado como la etiqueta de una clase general de objetos, no hay evidencia clara en el sentido de que Washoe fuese capaz de utilizar este signo para etiquetar comida, si no se le dejaba comer. Parece que Washoe era capaz de eligir un signo cuando se le presentaba un objeto, y que podía elegir un signo o un grupo de signos para hacerlos cuando quería que se le rascara, comer, salir, o que se le cogiera en brazos. Sin embargo, no hay evidencia que indique que fuese capaz de intercambiar estas funciones.

Dado que müchos de estos signos se convirtieron en parte de una situación contextual predecible que incluía secuencias y formas de acción y cooperación entre individuos, acaban por cumplir la función de señalar cuándo le toca a cada uno actuar y qué es lo que le toca hacer. Es decir, una función de estructuración de la conducta interindividual a un nivel presimbólico. Sin embargo, dado que tales signos continúan estando estrechamente ligados al contexto y derivan su propio sentido de la naturaleza del propio contexto y dado también que continúan teniendo una función semántica drásticamente limitada - sólo etiquetar en unos casos y solicitar en otros- no se alcanza el nivel de función representacional.

El vocabulario de Lana, como el de Washoe, se componía de dos tipos de lexigramas, los que servían para pedir cosas (tú, dar, Tim, Lana, manta, jugo, comida..., etc.) y los que se utilizaban para etiquetar cosas (tazas, caja, zapato, etc.). Sin embargo, a diferencia de Washoe, a Lana se le enseñó a etiquetar algunas (aunque no todas) de las cosas que pedía. Se le hizo etiquetar, por ejemplo, cosas y diapositivas de cosas, tales como sugus, jugo, pastel de judías, leche, manzana, naranja, plátano, comida y repollo; sin que le fuese permitido comer tales cosas (en esta prueba ciega de comida, Lana respondió correctamente 61 de las 65 veces, lo que supone un porcentaje de aciertos del 94 por 100). Ella era capaz también de pedir estas cosas si se las ofrecía el experimentador. Otros lexigramas tales como Tim, poner, dar y tú, se utilizaron únicamente en situaciones de pedir mientras que lexigramas tales como caja y panel se utilizaron solamente para pedirle a Lana que los nombrara. Las peticiones básicas de Lana eran similares a las de Washoe en el sentido de que se referían a las situaciones de comer, cambiar de lugar, hacer cosquillas y abrazarse o ponerse en contacto. Pero el contexto de producción de lexigramas era relativamente igual a lo largo de todas las situaciones en el caso de Lana y ella hizo peticiones tales como ?tü hacer puerta abrir, ?tú dar jugo a Lana, ?Lana salir de habitación o ?tú cosquillas Lana, todas ellas en un mismo lugar. Por ello el tipo de relación con el contexto de Lana difería en parte del de Washoe.

Lana tendía a iniciar cierto tipo de peticiones en ciertos momentos del día. Por ejemplo, ella recibía generalmente leche por la mañana; cuando empezó a pedir leche de forma espóntanea (es decir, sin que hiciese falta que viese a Tim delante de su cuarto con la jarra de leche), ella asoció estas peticiones con el momento del día, limitándose casi siempre a primeras horas de la mañana, tras la llegada de Tim. Dado que Lana no gozaba de la libertad física que tenía Washoe, no pudo estructurar los contextos tan fácilmente. A menudo tenía que conseguir que el experimentador mirase al panel y entrase en el cuarto antes de poder empezar a expresar una invitación no verbal para recibir cosquillas del tipo de las que se han descrito en Washoe.

Lana empezó a preparar frases incompletas tales como ?tú dar. dejando en suspenso la terminación hasta que pudiese obtener la atención del experimentador. Intentó combinaciones inusuales de lexigramas, al parecer con el objeto de llamar la atención del experimentador. Las combinaciones que tuvieron éxito las recordaba y las utilizaba en otras ocasiones. Rápidamente aprendió a formar combinaciones que provocaban cambios de las personas en el espacio. Sin embargo, no llegó a utilizar nada que no hubie- 


\section{Estudios}

se utilizado Washoe, que usaba la preposición fuera para describir la situación de un individuo o un objeto. Fuera era una paiabra que utilizaba Lana cuando quería que otro individuo se marchara «fuera». Si se colocaba una taza de comida fuera de su cuarto y se le preguntaba « ¿dónde taza?», sus respuestas eran al azar.

En definitiva, tanto Lana como Washoe hacían abundantes y variadas peticiones espontáneas. La aparición de tales peticiones vino determinada, muy probablemente, por tres importantes hechos. Primero, que el medio de comunicación (signos y el panel) estaba disponible todo el tiempo para iniciar interacciones con sus experimentadores. Segundo, que los experimentadores actuaban como si atribuyesen a las conductas una intención que no necesariamente existía en un principio (lo mismo se puede decir de las madres humanas, y muchos piensan que esto es un factor muy importante para permitir al niño pasar del estado de acción-reacción a la indicación gestual). Tercero, la naturaleza interindividual del paradigma de entrenamiento empleado en los proyectos de Lana y Washoe permitían la formación de roles dentro de rutinas estructuradas de interacción. En cambio, la Sarah de Premak no disponía fácilmente de los símbolos, el experimentador interpretaba su elección de símbolos no como comunicaciones sino como respuestas correctas o incorrectas, y la manipulación de símbolos realizada por Sarah no servía para alterar la conducta de sus acompañantes sino para producir un refuerzo $u$ otro ensayo.

\section{LA VERDADERA «SIMBOLIZACION»}

Entendemos las simbolización verdadera como el uso arbitrario de símbolos para referirse a objetos y sucesos que no están presentes en el tiempo y en el espacio. Esto implica «una visión del mundo como algo descomponible en cosas que mantienen su identidad y que pueden ser manipuladas mentalmente, de manera que incluso acciones y propiedades son redificables en palabras» (Bronowski y Bellugi, 1970). La capacidad para utilizar la simbolización aparece en el niño humano normal entre uno y tres meses después de un estado anterior en el que los referentes de las palabras no están claros, o en el mejor de los casos son extremadamente globales"y que, por tanto, se denomina más propiamente etapa de actuación pura (Greenfield, 1976; Braunwald, 1978; Bruner, 1978).

Braunwald (1978) estudió el desarrollo del lenguaje de su bebé durante el período de transición del lenguaje dependiente de contexto al prerrepresentacional. Registró todas las produc- ciones y sus contextos no lingüísticos entre los ocho y los veinte meses de edad. Durante el período prerrepresentacional su hija Laura empezó una serie de palabras de una sílaba en una amplia gama de contextos. Braunwald señala que lo que faltaba en las producciones de Laura durante este período era las convenciones lingüísticas y sociales, arbitrarias y culturalmente definidas, sobre la codificación de objetos y sucesos mediante producciones particulares, aunque las producciones se utilizaban en peticiones intencionales.

Inicialamente Laura utilizaba la palabra $b a$ de todas las formas siguientes: cuando quería leche, jugo o cualquier líquido en taza; cuando veía a su madre con una botella de leche; cuando quería jugar con la tapa de la botella de leche; cuando había terminado de beber y su taza estaba vacía; cuando hacía pompitas en su bebida; cuando miraba a una caja de botellas de leche; cuando derramaba la leche; cuando se echaba leche en algún sitio; cuando su madre ponía tazas en la mesa, y cuando quería beber más. $\mathrm{Pa}$ recía que $b a$ se refería a agua, taza, jugo, más, se acabó, verter, beber, taza, pompa, botella, caja y sabor rico, además de leche. Se utilizaba en situaciones en las que la conducta lingüística parecía servir para describir y comentar además de para pedir.

En unos pocos meses, las palabras paja, soplar, vacío, frío, taza, botella, pompa, más, verter, derramar, Laura, hacer, beber y jugo, aparecieron todas y fueron utilizadas en contextos en los que hasta entonces sólo decía ba. Por ejemplo, cuando I.aura derramaba su leche a la edad de un año y cuatro meses decía «adiós ba. Ununbax. Cuando al año, siete meses y veintocho días tiró otra vez la leche dijo «Laura tirar leche». Por tanto, en el niño humano, en el estado prerrepresentacional, existe un marcado vocal de una gran variedad de situaciones mediante un único elemento vocal. Más tarde se utilizan diferentes palabras para diferentes situaciones y se empieza a codificar verbalmente más detalles de la misma situación.

Cuando Laura tenía un año y siete meses decía frases tales como ala taza de Néstor guapo», «Laura tirar leche», «leche fría», aterminado», «mamá sopla paja», «echa jugo» y «Laura hace», todas ellas en contextos en los que su producción anterior había sido «bas. Estas producciones, todas dentro de un contexto de comida, son muy diferentes de las que se han informado para simios en contextos similares (Laidler, 1978). Por ejemplo, Terrace y colaboradores (en prensa) informan que Nim, en el contexto de comer, produjo frases tales como «comer yo», abeber Nim. «comer bebidas, «plátano yos, abeber té», «co. mer uva», «comer yo Nim» y auva comer Nim». 


\section{Estudios}

Todas las producciones de Nim eran esencialmente peticiones. En cambio, Laura hacía comentarios sobre los atributos de los utensilios de comer, sus propias acciones de derramar y las de su madre de verter, las características de la comida que estaba comiendo, las cosas utilizadas por la madre y la situación de haber terminado con la leche. Los comentarios de este tipo no se encuentran en ninguna producción lingüistica de los chimpancés. Esto constituye una diferencia clara y significativa en cuanto al uso de símbolos por parte de los niños y los chimpancés y resulta evidente incluso en los estadios más trempanos de la adquisición del lenguaje.

El uso del vocabulario y de los símbolos que hacen Nim, Washoe y Lana sugiere que los chimpancés tienden a utilizar los símbolos para hacer peticiones no específicas de contacto, juego, comida y cambio de lugar. Pero cuando el experimentador humano intenta enseñarles sím. bolos que denotan atributos más específicos de cada una de las situaciones (¿quién está comiendo?, ¿qué están comiendo?, la diferencia entre comer y beber, el acto de transferir comida de un individuo a otro, el hecho de las transferencia, etc.) el simio tiene dificultades para comprender los referentes de estos símbolos y la ra. zón por la cual se les exige ahora la utilización de estos símbolos adicionales para la obtención de la comida. Es por estas dificultades de comprensión por lo que los simios comienzan a encadenar juntos todos los símbolos que han sido efectivos en situaciones similares anteriores y parecen combinaciones tales como «dar naranja a.. mí dar comer naranja a-mí comer naranja dar a-mí comer naranja dar a-mí tú» (Terrace et. al., en prensa).

De hecho, signos tales como $t \bar{u}$, yo y dar son correctos prácticamente en todos los contextos en los que el simio pueda usarlos y su aparición resultará muy probablemente reforzada por el experimentador. Uno o más de estos signos de uso universal $(t \bar{u}$, yo, más, dar, y el nombre del propio animal) combinados con otros signos producirá un resultado que parecerá una combinación con sentido, pero tales combinaciones carecerán de la especificidad referencia de las combinaciones que hacen los niños. Los datos sobre las peticiones espontáneas de Washoe y Nim apoyan la idea de que los simios utilizan ciertas palabras más como «comodines» que como elementos sintácticos. Por ejemplo, 17 de entre las 25 combinaciones de dos signos más frecuentes de Nim contenían una o más de tales palabras (Terrace et al., en prensa).

Otro indicio en el sentido de que es posible que los simios no entiendan el significado comunicativo de los signos que han aprendido a usar, es que en ningun momento llegan a participar en conversaciones de varias preguntas y respues. tas alternativas entre los interlocutores. En los niños, sin embargo, se ha indicado que tras la aparición del balbuceo inician intercambios vocales sucesivos y alternantes con la madre. Terrace (1979) señala que Nim no alcanzó este nivel de intercambio conversacional, incluso tras cuarenta y seis meses de constante entrenamiento trenamiento en el uso de signos. Nim interrumpía, frecuentemente, a sus profesores dando la impresión de que estaba ansioso por hacer un signo que les había visto producir, o una ráfaga de signos, todo ello en un intento de conseguir comida. Aunque esto no fue descubierto por sus entrenadores en un principio, se hizo evidente posteriormente cuando se estudiaron detenidamente las grabaciones en video de las sesiones con Nim. Interrupciones análogas fueron observadas por Terrace en películas de Washoe y Koko. Este tipo de interrupciones se oponen drásticamente a lo que ocurre en los primeros intercambios entre niños y adultos. El niño humano, a diferencia del chimpancé, trata de captar la atención antes de comenzar la producción verbal, al objeto de subrayar el hecho de que se va a emitir una señal importante y para establecer la expectativa que cumplirá la producción de tal señal, provocando una alteración de la conducta que se está desarrollando.

Por tanto, los chimpancés, al igual que los niños, aprenden a utilizar símbolos como parte de las rutinas de interacción social. Son capaces de discriminar varios conjuntos de circunstancias en los que la producción de determinados símbolos es más apropiada y logra la obtención de un objetivo. También, al igual que los niños, aprende a iniciar estas rutinas de interacción social a base de producir símbolos. Sin embargo, a diferencia de los niños, los simios no parecen poder pasar de este punto. Hasta la fecha no hay evidencia en el sentido de que Washoe, Sarah, Lana, Koko o Nim adquiriesen el nivel de la verdadera simbolización.

De hecho, la mayoría de los estudios sobre el lenguaje de los simios no han ido, verdaderamente, más allá del nivel de comunicación básica del chimpancé. En su medio natural, los chimpancés poseen un sistema de comunicación gestual espontáneo, mediante el cual pueden pedir calma, pedir permiso para coger un poco de comida e iniciar interacciones de cosquillas, persecución, acicalamiento y sexuales. Las madres chimpancés pueden indicar mediante gestos que otros han de alejarse de sus hijos y cualquier individuo puede solicitar la ayuda de otros durante enfrentamientos agresivos. Pero estos gestos están limitados a las interacciones sociales y ninguno de ellos contiene información sobre conductas relacionadas con algo que no esté pre- 
sente. Nunca se ha visto a un chimpancé salvaje indicar gestualmente una acción que deseara que otro chimpancé hiciese sobre un objeto inanimado para su propio beneficio. Es precisamente este iipo de peticiones sobre objetos lo que constituye la mayoría de los primeros intercambios lingüisticos entre la madre y el niño (Bruner, 1978).

Cuando los experimentadores han conseguido enseñar a los simios a hacer gestos o símbolos para iniciar interacciones tales como las cosquillas, los acicalamientos o los abrazos, tales gestos o símbolos han servido únicamente para substituir o acompañar a los gestos no verbales que los simios hubieran utilizado naturalmente en estos casos. Los intentos en el sentido de incrementar la especifidad del referente dentro de una situación han acabado en una simple cadena de símbolos, ya que el chimpancé ha aprendido más símbolos para algo que para él es la misma situación general contextual. Por esto, los chimpancés tienden a formar cadenas de cinco-seis elementos del tipo de tú a-mí dulce bebida dar a-mí, mientras que los niños forman cadenas de seis elementos del tipo de la-madre-de Johnny me dió un-poco-de belado. Los chimpancés han utilizado los símbolos solamente como indicadores del deseo de que se les pase comida, mientras que los niños rápidamente describen y registran una serie de aspectos de hechos pasados. Por tanto, parece que los chimpancés, incluso sometidos a un entrenamiento lingüístico intensivo, han permanecido al nivel de comunicación que poseen naturalmente, el de ser capaces de indicar de forma general que desean que otro realize algo en o para ellos, cuando existe un referente único y no ambiguo.

En realidad, los estudios sobre el lenguaje de los simios han fracasado a la hora de obtener la verdadera simbolización, en parte debido a que se han centrado casi exclusivamente en el aspecto de la producción. A Washoe, Lana y Nim se les enseñaba cómo nombrar, pero a ninguno de le pedía que demostrase una competencia receptiva equivalente. Algo tan simple como dar una cosas en respuesta a una petición mediante símbolos, exige que el simio vaya más allá de la conducta ritualizada que consiste en hacer símbolos para lograr objetivos concretos. Exige que el simio se fije en sus acciones y las coordine con respecto a objetos, según los deseos simbólicamente expresados por otros. Esto supone tanto una orientación conceptual ajena al nivel de comunicación natural de los simios como una orientación social hacia lo ajeno. Cooperar, atender a, y dar objetos específicos de entre un conjunto, cada uno a partir de una petición simbólica, son conductas que no se encuentran normalmente en los simios. Por tanto, dado que el aspecto receptivo de la utilización de símbolos es importante de cara a una verdadera simbolización, esta capacidad ha de ser enseñada también a los simios. Aún màs, no sólo supone el reconocimiento de simbolos, sino que es necesario desarrollar una elaborada estructura de dar-objetos, dentro de un marco social ajeno al chimpancé en su estado natural. La falta de atención a tales hechos puede haber entorpecido gravemente la capacidad de comprensión de los simios respecto de los símbolos que se dice que utilizan.

Más o menos se puede decir que en la mayoría de los trabajos sobre el lenguaje en simios los gestos o símbolos no han supuesto generalmente más información de la que venía dada por el contexto y las acciones no verbales de los participantes. Unicamente cuando un símbolo es utilizado para referirse a información acerca de comidas u objetos específicos, o para referirse a información sobre comida u objetos ausentes, se puede decir que añade valor informativo a lo que ya es inhererite al contexto de interacción. Creemos que Sherman y Austin son los únicos simios en los que se ha demostrado la capacidad de usar símbolos de esta manera (Savage-Rumbaugh et al. 1978a,b).

Los investigadores del lenguaje en simios no deben limitarse a describir lo que los simios dicen. Han de atender al contexto no verbal total y deben evaluar el valor informativo de los símbolos per se. Esto exige el registro en video de todos los aspectos del entrenamiento y las pruebas. Las dificultades a la hora de interpretar y registrar con cualquier otro método todos los as pectos relevantes de las conductas y las tareas, desafia los límites de las hojas de registro y las grabaciones magnetofónicas. Habrá que desarrollar métodos para investigar los aspectos semánticos de los varios tipos de producciones simbólicas y de las condiciones lingüísticas socioconductuales inherentes. Los experimentadores deben dejar de buscar similitudes superficiales entre los simios y los niños, y en su lugar deben investigar las capacidades cognitivas que subyacen a los procesos simbólicos. 


\section{Estudios}

\section{Referencias}

BATES, E. 1976. Language and Context: The Acquisition of Pragmatics. Academic Press.

BRAUNWALD, S. R. 1978. Context, word and meaning. En Action, Gesture and Symbol: The Emergence of Language, ed. A. Lock, pp. 486-527. Academic Press.

BRONOWSKI, J. S. y U. BELLUGI. 1970. Language, name and concept. Science 168: 669-73.

BROWN, R. 1973. A First Language: The Early Stages. Harvard Univ. Press.

BRUNER, J. S. 1973. Organization of early skilled action. Child Development 44: 1-11.

- 1974/75. From communication to language: A psychological perspective. Cognition 3: 255-87.

- 1978. The role of dialogue in language acquisition. En The Child's Conception of Language, ed. A. Sinclair, R. J. Jarvella y W. J. M. Levelt, pp. 241-55. Berlin: Springer-Verlag.

CHOMSKY, N. 1968. Language and Mind. Harcourt Brace Jovanovich.

CLARK, R. A. 1978. The transition from action to gesture. En Action, Gesture and Symbol: The Emergence of Language, ed. A. Lock, pp. 231-57. Academic Press.

CURTISS, S. 1977. Genie: A Psycbolinguistic Study of a Modern-Day aWild Child». Academic Press.

DINGWALL, W. O. 1979. The evolution of human communication systems. En Studies in Neurolinguistics, vol. 4, ed. H. Whitaker y H. A. Whitaker. Academic Press.

FOUTS, R. S. 1972. The use of guidance in teaching sign language to a chimpanzee. J. Comparative and Physiological Psych. 80: 515-22.

- 1973. Acquisition and testing of gestural signs in four young chimpanzees. Science 180: 978-80.

- 1974. Capacities for language in the great apes. En Proceedings of the 18th International Congress of Anthropological and Ethnological Sciences. The Hague: Mouton.

FOUTS, R. S., W. CHOWIN y L. GOODIN. 1976. Transfer of signed responses in American Sign Language from vocal English stimuli to physical object stimuli by a chimpanzee (Pan.). Learning Motivation 7: 458-75.

FOUTS, R. S., W. CHOWIN y KIMBALL. 1976. Comprehension and production of American Sign Language by a chimpanzee (Pan.). Paper presented at the 21 st International Congress of Psychologists, Paris.

FOUTS, R. S. y R. L. MELLGREN, 1976. Language, signs and cognition in the chimpanzee. Sign Language Studies 13: 319-46.

GALLUP, G. C., J. L. BOREN, G. J. GAGLIANO y L. B. WALLNAU. 1977. A mirror for the mind of man, or, Will the chimpanzee create an identity crisis for Homo sapiens? J. Human Evolution 6: 303-14.

GARDNER, B. T. y R. A. GARDNEK. 1969. Teaching sign language to a chimpanzee. Science 165: 664-72.

- 1971. Two way communication with an infant chimpanzee. En Behavior of Nonhuman Primates. ed. A. M. Schrier y F. Stollnitz. Academic Press.

- 1972. Communication with a young chimpanzee: Washoe's vocabulary. En Modeles animaux du Comportement Humain, ed. R. Chauvin, pp. 241-64. Paris: Centre National de la Recherche Scientifique.

- 1973. Teaching sign language to the chimpanzee Washoe (16 mm sound film). State College, PA: Psychological Cinema Register.

- 1974a. Comparing the early utterances of child and chimpanzee. En Minnesota Symposium on Child Psychology, vol. 8, ed. A. Pick, pp. 3-23. University of Minnesota Press.

- 1974b. Teaching sign language to a chimpanzee VII: Use of order in sign combinations. Bull. Psychonom. Soc. 4: 264.

- 1975. Evidence for sentence constituents in the early utterances of child and chimpanzee. J. Exp. Psychol.: General 104: 244-67.

- 1978a. Emergence of language. Paper presented at AAAS, Annual meeting, Washington DC, 16 february 1978.

- 1978b. Comparative psychology and language acquisition. En Psychology: The State of the Art, ed. K. Salzinger y F. Denmark, pp. 37-76. Annals of the New York Academy of Sciences, vol. 309.

GILI, T. V. Conversations with Lana. 1977. En Language Leaming by a Chimpanzee: The LANA Project, ed. D. M. Rumbaugh, pp. 225-46. Academic Press.

GREENFIELD, P. M. 1973. Who is :Dadas? Some aspects of the semantic and phonological development of a child's first words. Language and Speech 16: 14-43.

- 1979. The Structure of Communication in Early Language Development. Academic Press.

GRIFFIN, D. R. 1976. The Question of Animal Awareness: Evolutionary Continuity of Mental Experience. The Rockefeller Univ. Press.

HILL, J. H. 1978. Apes and language. Ann. Rev. Antbropol. 7: 89-112.

JENKINS, H. M. y B., R. MOORE. 1973. The form of the autoshaped response with food or water reinforcers. J. Exp. Analysis of Behavior 20: 163-81.

JENKINS, J. J., y D. S. PALERMO. 1964. Mediation processes and the acquisition of linguistic structure. En The Acquisition of Language, ed. U. Bellugi y R. Brown, pp. 141-68. Report of the Fourth Conference sponsored by the Committee on Intellective Processes Research of the Social Sciences Research Council, vol. 29.

LAIDLER, K. Language in the orangutan. 1978. En Action, Gesture and Symbol: The Emergence of Language, ed. A. Lock, pp. 132-55. Academic Press.

LENNEBERG, E. H. 1967. Biological Foundations of Language. John Wiley and Sons.

- 1971. Of language, knowledge, apes and brains. J. Psychol. Research 1: 1-29. 


\section{Estudios}

LIMBER, J. 1977. Language in child and chimp? Am. Psych. 32: 280-95.

MEDDIN. J. 1979. Chimpanzees, symbols and the reflective self. Soc. Psych. Quart. 42: 99-109.

MOUNIN, G. 1976. Language, communication, chimpanzees. Cur. Anthropol. 17: 1-7.

NEISON, K. Firsts steps in language acquisition. J. Am. Acad. Child Psychiatry. (en prensa).

PATTERSON, F. 1978. The gestures of a gorilla: Sign language acquisition in another pongid species. Brain and Language 5: 72-97.

PETTTTO, L. A. y M. S. SEIDENBERG. 1979. On the evidence for linguistic abilities in signing apes. Brain and Language 8: 162-83.

PREMACK, D. 1970. A functional analysis of language. J. Exp. Analysis of Behavior 14: 1-19.

- 1971. On the assessment of language competence in the chimpanzee. En Behavior of Nonbuman Primates, vol. 4, ed. A. M. Schrier y F. Stollnitz, pp. 185-228. Academic Press.

- 1972. Teaching language to the ape. Sci. Am. 227: 92-99.

- 1976. Intelligence in Ape and Man. Hillsdale, N: J.: Lawrence Erlbaum Assoc.

- 1979. Trivial language in a nontrivial mind. Paper presented at Western Psychological Assoc. annual meeting. San Diego, CA, 6 April 1979.

PYLYSHYN, G. W. 1977. What does it take to bootstrap a language? En Language and Thought, ed. J. MacNamara, pp. 37-45. Academic Press.

RUMBAUGH, D. M., ed. 1977. Language Learning by a Chimpanzee: The LANA Project. Academic Press.

RUMBAUGH, D. M. y T. V. GILL, 1977 . Lana's acquisition of language skills. En Language Learming by a Chimpanzee: The LANA Project, ed. D. M. Rumbaugh, pp. 167-92. Academic Press.

RUMBAUGH, D. M., H. WARNER yE. VON GLASERSFED. 1977. The Lana project: Otigin and ratics. En Language Leaming by a Chimpanzee: The LANA Project, ed. D. M. Rumbaugh, pp. 87-90. Academic Press.

SAVAGE-RUMBAUGH, E. S. 1979. Symbolic communication: Its origins and early development in the chimpanzee. En New Directions in Child Development, ed. H. Gardner and D. Wolf, pp. 1-16. San Francisco: Jossey-Bass.

SAVAGE-RUMBAUGH, E. S., y D. M. RUMBAUGH. 1978. Symbolization, language, and chimpanzees: A theoretical reevaluation based on initial language acquisition processes in four young Pan troglodytes. Brain and language 6: 265-300.

- 1979. Initial acquisition of symbolic skills via the Yerkes computerized language analogue system. En Language and Communication: Primate to Child, ed. R. Schiefelbusch and J. Hollis. Univ. Park Press.

- Language Analogue Project, phase 2: Theory and tactics. En Child Language, vol. 2, ed. K. Nelson. Grardner Press (en prensa).

SAVAGE-RUMBAUGH, E. S., D. M. RUMBAUGH y S. BOYSEN. 1978a. Symbolic communication between two chimpanzees (Pan troglodytes). Science 201: 641-44.

- 1978b. Linguistically mediated tool use and exchange by chimpanzees (Pan troglodytes). The Behavioral and Brain Sciences 1: 539-54.

- Symbolic communication in apes: A critique of the state of the art. En Language, Mind and Brain, ed. T. W. Simon and R. J. Scholes. Lawrence Erlbaum, Inc. (en prensa).

SEBEOK, T. A. 1972. Perspectives in Zoosemiotics. The Hague: Mouton.

SEBEOK, T. A. y J. UMIKER-SEBEOK. 1979. Performing animals: Secrets of the trade. Psychology Today 13 (6): 78-91.

SEIDENBERG, M. S. y L. A. PETITTO. 1979. Signing behavior in apes: A critical review. Cognition 7: 177-215.

SKINNER, B. F. 1953. Science and Human Behavior. Macmillan.

- 1957. Verbal Behavior. Prentice-Hall.

STEKIIS, H. D. y M. J. RALEIGH. Requisites for language: Interspecific and evolutionary aspects. En Neurobiology of Social Communication in Primates: An Evolutionary Perspective. Academic Press (en prensa).

TERRACE, H. S. 1979. Is problem-solving language? J. Exp. Analysis of Behavior 31: 161-75.

TERRACE, H. S., L. A. PETITTO, R. J. SAUNDERS y T. G. BEVER, 1979. Can an ape create a sentence? Science 206: 891-900.

- Can an ape create a sentence? En Children's Language, vol. 2, ed. K. Nelson. Gardner Press (en prensa).

WHITE, S. J. 1978. Are LASSes (Language Acquisition Socialization Systems) better than LADs (Language Acquisition Devices)? En Papers in Anthropology and Linguistics, ed. M. Ebihara and R. Gianutsos, pp. 53-64. Annals of the New York Academy of Sciences, vol. 318. 